\title{
TERRITORIALIDADES E SABERES LOCAIS: muros e fronteiras na construção do saber acadêmico
}

\author{
Cecília Bastos da Costa Accioly ${ }^{*}$
}

\begin{abstract}
Neste artigo, contextualizo os paradigmas atuais que possibilitam a análise do sistema de organização cultural (os saberes acadêmicos e locais) e as instituições de ensino superior. Proponho a discussão das diferenciações disciplinares e hierarquias arraigadas em nossa sociedade e, em princípio, da superação através dos olhares sobre as regiões fronteiriças da construção social. Sustento a relação dos saberes formadores das culturas, ressaltando seu momento de separação e hierarquização devido a uma aplicação do método científico formador da construção do conhecimento acadêmico; e a atual discussão sobre sua re-união sob a ótica de uma epistemologia do cotidiano.

PALAVRAS-CHAVE: territorialidades, saberes locais, saber acadêmico, epistemologia do cotidiano.
\end{abstract}

\section{INTRODUÇÃO}

A mudança de paradigmas que presenciamos vem permitir a inauguração e discussão de novas terminologias para falar dos atuais fenômenos sociais. Os conceitos buscaram se manter fixos e imutáveis por longo tempo, de acordo com suas relações positivistas com o saber, mas hoje se encontram num processo de revisão semântica e etimológica. Não pretendo esgotar aqui essa discussão terminológica, mas distinguir os termos que circundam as noções de territorialidades e saberes locais para dar conta da progressão desta pesquisa. ${ }^{1}$

A sociedade contemporânea, onde me encontro cidadã, vem se transformando e passando por um processo compreendido como de

* Doutoranda pelo Programa de Pós-Graduação em Artes Cênicas da UFBA (Bolsa CNPQ). Participa do Grupo Interdisciplinar de Pesquisa e Extensão em Contemporaneidade, Imaginário e Teatralidade (GIPECIT) UFBA.

Avenida Araújo Pinho 292 - Campus do Canela. Cep: 40110-150.

Salvador - Bahia - Brasil. cecidanca@ig.com.br

${ }^{1}$ Artigo resultante da revisão bibliográfica da pesquisa de mestrado e doutorado da autora. “desconstrução”. Esse fenômeno é aqui empregado no sentido derridariano de revisão de padrões, observado e analisado como mudança das relações com as instituições formadoras do social. A concepção terminológica do título reflete a atitude de perceber esse social imerso num mal-estar ${ }^{2}$ gerado pela imposição das escolhas. Os indivíduos estavam fadados a relacionar-se com a concepção de nacionalismos, imbricados ao poder estatal emergente. Esse poder, substituído pelo liberalismo, condena o homem a outro suplício - a liberdade de escolhas.

Esse homem, posicionado na encruzilhada da submissão a um estado constituído e do poder de locar-se por si, percebe-se ator efetivo de si mesmo, tornando urgente a proposição consequente da atitude reflexiva sobre si, sobre os outros e o ambiente.

Nessa conjuntura, termos como territorialidades, saberes locais e identidades assumem particular importância para a compreensão dos fenômenos sociais, A seguir, dedico-me à sua discussão.

${ }^{2}$ Termo empregado por Zigmund Bauman (1998), ao abordar a liberdade de escolha que, a seu ver, permeia a pósmodernidade. 
TERRITÓRIOSE CULTURAS: muros e fronteiras

Pertencemos a um território, não o possuímos, guardamo-lo, habitamo-lo, impregnamo-nos dele. Além disto, os viventes não são os únicos a ocupar o território, a presença dos mortos marca-o mais do que nunca com o signo do sagrado. Enfim, o território não diz respeito apenas à função do ser ou ao ter, mas ao ser. Esquecer este princípio espiritual e não material é se sujeitar a não compreender a violência trágica de muitas lutas e conflitos que afetam o mundo de hoje: perder seu território é desaparecer.

Bonnemaison e Cambrèzy, 1996

Para início desta argumentação, faz-se necessário esclarecer o sentido que atribuo aos termos território e territorialidades, suas particularidades e sua relevância para a compreensão desta pesquisa.

O conceito de território, comumente vinculado à Geografia, por estar diretamente relacionado às questões de espacialidade, tem sido alvo de discussões frequentes em diferentes áreas do conhecimento. Costa (2007) apresenta as múltiplas perspectivas assumidas pelo termo sob a ótica de diversas disciplinas. A partir da compreensão dessa análise, assumo o termo territorialidades para identificar o território simbólico, ou o que considero "espaço de referência para a construção de identidades” (p.35), enfatizando as questões simbólicoculturais.

Desse autor, aproprio-me de uma vertente básica de concepção de território: a cultural. Segundo ele, essa é a mais subjetiva, como “... produto da apropriação/valorização simbólica de um grupo em relação ao espaço vivido" (Costa, 2007, p.40). Vale salientar que, para este estudo, cabe a vinculação dessa vertente a uma segunda - a política -, que enfoca a relação entre espaço e poder. Não descarto os demais conceitos referentes ao termo, mas acredito relevante fazer um recorte determinado para um melhor direcionamento do leitor aos propósitos desta análise.

Inicio meus argumentos com a definição de Milton Santos (2008) do território concebido através de um olhar primeiramente geográfico-econô-

\footnotetext{
${ }^{3}$ Apud Costa, 2007. p.73.
}

mico, o território usado. Ele sugere o território não apenas como

... superposição de um conjunto de sistemas naturais e um conjunto de sistemas de coisas criadas pelo homem. [...] é o chão e mais a população, [...] uma identidade, o fato e o sentimento de pertencer àquilo que nos pertence. [...] é a base do trabalho, da residência, das trocas materiais e espirituais e da vida, sobre os quais ele influi (p.96-97)

Ou seja, território é lugar de afirmação de culturas, economias, políticas. Local geograficamente estipulado pela necessidade específica de determinadas sociedades de cristalizar seu tempo num espaço, de estabelecer um local de partilha de experiências, construção de mitos comuns, de significar sua existência através da proximidade com o outro com quem se identifica e compartilha uma história comum - a história do lugar. Esse autor identifica uma relação direta entre as feições naturais do território e seu funcionamento por uma adaptação dos homens com pequena intermediação técnica. Seu valor é atribuído pelo uso, regendo as manifestações da vida social.

Esse uso desvincula-se do pressuposto utilitarista, pois considero que o espaço propriamente dito faz parte do cotidiano de seus habitantes na criação e recriação dos mitos e símbolos, caracterizando-os como grupo. Eles se vinculam pela sensação de pertencimento gerado pela apropriação simbólica do espaço, através do princípio de identificação - o que torna o território um "construtor de identidade" -, considerando que o grupo não se apropria de determinado território, mas identifica-se com ele. A relação com o espaço torna-se afetiva, ou o que, preferencialmente e a exemplo de Michel Maffesoli (2006), chamarei de afetual.

Partindo dessa concepção de pertencimento, aproprio-me-ou melhor-identifico-me com uma concepção especifica da territorialidade, atribuída à Antropologia, o neotribalismo. Introduzida por esse autor, essa concepção apoia-se na afirmação de que o período atual caracteriza-se por ser "empático", pela indiferenciação, pelo "perder-se em um sujeito coletivo" (2006, p.38). Segundo ele, percebemonos numa socialidade empática, em substituição ao 
social racionalizado da modernidade.

Ainda de acordo com Maffesoli, esses microgrupos sociais, a que chamamos tribos, podem ser avaliados através da categoria "comunidade emocional”, de análise sócio-histórica de Max Weber, assumindo as características de efemeridade, "composição cambiante”, inscrição local, "a ausência de uma organização", e a estrutura quotidiana. Esse último passa a ser o substrato sobre o qual se articularão todas as representações do sólido laço social que compõe o grupo.

Essa concepção pós-moderna de território nos leva a compreender a dissolução das fronteiras forjadas na ordem dos nacionalismos impostos pela organização político-econômica préestabelecida. Os enormes muros construídos geográfica e cartesianamente começam a não mais atender aos anseios da atual socialidade. Os traços cartográficos dos polígonos começam a ser superpostos pelas linhas pontilhadas pelo cotidiano. As comunidades passam a ser constituídas pela identificação do dia a dia. Obanal passa a ser determinante para a sensação de pertencimento que gera as diferentes fronteiras, tracejadas, líquidas, moldáveis ao simbólico, àquilo que é compartilhado, sentido pelo nós.

E o que vem a ser esse nós?

No neotribalismo, o indivíduo passa a importar menos que a pessoa, que deve representar seu papel numa cena global regido por regras precisas, criadas e compartilhadas pela ética. A estética do nós, caracterizada pelo sentir em comum, é a abertura para o Outro, o que conota a proxemia (espaço, local em que se representa o destino comum), uma estética favorecida pelo espaço. A ética que rege esses reagrupamentos opõe-se à moral imposta e abstrata da modernidade, é empática e proxêmica, originária do próprio grupo, produzida pelo espaço compartilhado. É gerada a partir da união do grupo pela identificação, pelo devotamento que reforça aquilo que é comum a todos. O grupo passa a ser um lugar em que a pessoa se percebe a serviço de, e não apenas um lugar de refúgio. “... é, por força das circunstâncias, porque existe proximidade (promiscuidade), porque existe a partilha de um mesmo território (seja ele real ou simbólico), que vemos nascer a ideia comunitária e a ética que é o seu corolário" (Maffesoli, 2006, p.46). Vale salientar que essa comunidade constitui uma moralidade própria, a partir do que o autor chama de "experiência ética”, que esgota sua energia na sua própria criação - ou seja, é voltada para o presente-, reafirmando seu sentimento de si através da criação de seus rituais cotidianos, repetitivos, que dá segurança à ligação entre a ética comunitária e a solidariedade estabelecida.

Considero essa experiência ética, atrelada à estética, a nova concepção de fronteira: a fronteira banal e cotidiana, não cartográfica, que faz com que haja o ajustamento de uns aos outros, a um território determinado e ao meio natural. Sendo originária de relações frequentemente conflituais, torna-se flexível apesar de longeva, sendo a "expressão mais característica do querer-viver social." (2006, p.53).

A partilha do território pela experiência cotidiana, que torna o reagrupamento coeso e fluido ao mesmo tempo, substitui e vai de encontro à falsa sensação de segurança imposta a partir dos pressupostos do receituário da Modernidade.

De acordo com Bauman (1998, p.20), “... pode-se definir a modernidade como a época, ou o estilo de vida, em que a colocação em ordem depende do desmantelamento da ordem 'tradicional', herdada e recebida; em que 'ser' significa um novo começo permanente.”. Ordem e Progresso, palavras estampadas em nossa bandeira nacional, são a evocação da modernidade. Uma era criada para e pela rotina de eliminação de sujeira, um eterno novo começo em busca da artificial pureza gerada pela eterna ordem e ininterrupta rotina de limpeza. "A sujeira é essencialmente desordem [...] ela existe ao olhar do observador [...] Se o desasseio é coisa inapropriada, devemos atacá-lo através da ordem. O desasseio ou a sujeira é o que não deve ser incluído se um padrão precisa ser mantido." (Douglas, 1970 apud Bauman, 1998. p.18, grifos meus). A limpeza, símbolo do processo de exclusão para a manutenção dos padrões estabelecidos, 
mantidos a qualquer custo, fomentando a criação dos marginais.

Os estranhos da modernidade tornam-se a síntese da sujeira, criaturas à margem do padrão estabelecido, aqueles que não se furtam a questionar as verdades absolutas e inquestionáveis. Alvos dos mantenedores das utopias modernas, sempre constituíram uma ameaça ao "mundo perfeito" - permanente, idêntico a si mesmo, fixo e imutável, sem obscuridades, transparente, harmônico, sem estranhos -, ao totalitarismo de uma ordem nova e final, geradora de uma sociedade em eterno estado de atenção para a manutenção das coisas em seus devidos lugares.

Inimigas da desordem e num mundo industrial imerso na mudança, as imposições fomentavam as políticas totalitárias extremistas, buscandose sempre combater novas anomalias e prevenir possíveis modificações de padrões, numa constante luta contra o surgimento de novas sujeiras. A insegurança passa a reinar absoluta. A incerteza e a desconfiança se estabelecem pela ineficiência das habilidades de purificação em acompanhar a criação de novas categorias de sujeira. A Modernidade pressupõe a massa perfeitamente homogênea de humanos idênticos. Um amálgama sem nuances, que atenda à necessidade de expurgar qualquer continuação da velha ordem remanescente do período que a antecede, uma coletividade que representasse o asséptico destino comum da humanidade, harmônico, perfeito, inquestionável, absoluto.

Acredito que a criação de ideais de pureza não é uma exclusividade da Era Moderna, mas de todas as sociedades. Refiro-me, especificamente, ao ideal moderno pela sua influência direta na atualidade, na construção do social e da socialidade, e do ideal de educação de que decorre a instituição de ensino superior no Brasil, sobre a qual me dedico nestes escritos.

Os estranhos a que me refiro não se encaixavam no mapa cognitivo, moral ou estético do mundo moderno. A transgressão de que eram culpados turvava a tão buscada transparência de seu tempo, borrava as fronteiras, exalava incertezas. Na guerra, para expurgá-los, segundo Bauman
(1998), criaram-se duas estratégias conhecidas e defendidas por nossas instituições ainda mantidas sob a ótica moderna. A primeira é a antropofágica, que consistia na assimilação da diferença tornando-a semelhante, abafando as distinções culturais ou linguísticas, proibindo as tradições e lealdades que não alimentam a conformidade com a ordem nova, promovendo e reforçando uma única medida. A segunda é a antropoêmica que consistia na exclusão das criaturas, banindo-as dos limites para além das fronteiras do território, sem comunicação com o lado de dentro, confinando-as aos guetos, cerceando seus direitos. No caso de nenhuma das alternativas darem certo, restava a destruição física. Considero que um dos motivos da proliferação dessas criaturas consideradas indesejáveis talvez fosse o processo de sobrevivência a partir da construção da identidade individual.

Durante a construção de sua sociedade, o Estado Moderno pretendia libertar seus indivíduos de suas identidades herdadas, levando-os a se responsabilizar pela realização de suas identidades, que, após escolhidas, tornavam-se fixas e imutáveis, alheias ao poder intermediário das comunidades e tradições. Para esse projeto, cada indivíduo era considerado uma tábula rasa, lisa, sem qualquer indício de marca. Suas inscrições datavam de sua introdução ao social, do momento em que decidia sua identidade, livre de qualquer herança, qualquer conexão com os saberes e suas ancestralidades.

A exacerbação da individualidade moderna não encontra condições de continuidade no contexto da pós-modernidade. Essa identidade, forjada de forma fixa e imutável, não encontra um substrato sólido e passa a ser revista. O reinado da incerteza demonstra a fragilidade do mundo construído sob a égide do autoritarismo estatal, da verdade absoluta e da homogeneidade imposta para o purismo. Os estranhos buscam seus direitos de se perceber parte de algo, de ser reconhecidos como integrantes da sociedade. Os guetos constituem comunidades baseadas em ajuda mútua. O pertencimento dá origem a novos estranhos, a incerteza também dá origem a novos estranhos, as- 
sim como a dimensão econômica do consumo e do capital neoliberal dá origem a novos estranhos. É preciso rever as fronteiras de exclusão dos estranhos, pois há novos limites que não podem ser determinados a priori no contexto da incerteza cotidiana.

As pessoas se buscam e se repelem num ciclo constante da busca pela sensação de segurança. Esse movimento gera um sentir comum (estética), que gera, por sua vez, novas regras de convivência - por e para a convivência -, assumindose um laço coletivo (ética) que é re-afirmado no cotidiano através dos costumes. De acordo com Maffesoli (2006, p.54), os costumes são “... o conjunto dos usos comuns que permite a um conjunto social reconhecer-se como aquilo que é [...] é o não dito, o 'resíduo' que fundamenta o estar-junto".

É o costume que faz a comunidade existir como tal. Ele, aliado à inscrição local, constitui a noção de pertencimento tribal. A relação interindividual liga as pessoas também a um determinado lugar. A partilha do território, a proxemia, leva-as a organizar suas vidas em torno de mitos comuns, não mais uma história universal, mas a experiência do dia a dia. O território adquire contornos físico-simbólicos.

O reforço à heterogeneidade pós-moderna põe em destaque a multiplicidade de novos agrupamentos, que, por sua vez, movidos pelo sentir em comum, elaboram uma memória coletiva que termina por se constituir em cultura. Originária de uma experiência em comum, é constituída de ajustamentos que promovem uma espécie de equilíbrio a partir do heterogêneo.

Assimilando a noção de cultura denotando expressão ou reflexo de determinada sociedade (Burke, 2005), e entendendo-a como herança de valores e objetos compartilhada por um grupo humano (Bosi, 1992), passo a compreender a existência das múltiplas culturas relacionadas à multiplicidade de memórias coletivas geradas no território das tribos. Acredito ser a cultura um conjunto de técnicas, mitos e rituais eficientes concebidas para a sobrevivência de determinado agrupamento de pessoas. Esse agrupamento é fomen- tado pelas possibilidades de criação hiperbólica de compreensão de mundo em comum, bem como o vislumbre da segurança perdida nas possibilidades de escolha da pós-modernidade, com o fim dos nacionalismos.

Essas concepções de cultura afirmam identificações, gerando o que Hall (2006) nomeia identidades culturais, ou aspectos identitários que emergem da sensação de pertencimento a determinada sociedade, território ou tribo. Anteriormente fomentadas pela nacionalidade, contribuíram para criação de padrões homogeneizantes de comportamento-comunicação, educação, idioma etc. -, produzindo sentidos sobre a nação. Com a multiplicidade de tribos, o processo de formação da cultura torna-se cotidiano, através da partilha de territórios, sentimentos e memórias. Esse termo passa a ser sinônimo de multiplicidade. Vinculada ao vaivém de pessoas entre tribos, num processo de deriva, enraizamento e reencaixe constante, as múltiplas culturas se tornam um processo dinâmico de reinvenção e reafirmação. Arraigadas ao território espaço-símbolo, elas se tornam parte da estrutura de sobrevivência tribal, estimulando a reestruturação da relação de seus componentes com a transmissão e perpetuação dos hábitos e do conhecimento advindo deles.

\section{OSABER E O SABER-FAZER}

O termo saberes é aqui empregado como o conhecimento criado para a transmissão dos hábitos forjados para as culturas e territórios sociais, com possibilidade de reprodutibilidade, reflexão, transformação e adaptação dos indivíduos.

Considerando os limites dos territórios uma membrana que possui permeabilidade seletiva e inevitavelmente se comunica com outras membranas e com o meio que as circunda e permite sua sobrevivência -, percebo que essa máxima da citologia permite conferir duas proposições históricas de construção da relação entre esses territórios: as criadas no ambiente interno, pressupondo um purismo das relevâncias desses saberes, cons- 
truindo uma fortaleza territorial cercada por um enorme muro de concreto; e as criadas a partir da relação com o meio, influenciando inevitavelmente o exterior e estabelecendo um conhecimento híbrido, resultando no saber de fronteira, que não é nem o bem nem o mal, mas o agrupamento das hipérboles, as saídas construídas no fazer de comunidade.

O Conhecimento ficou, assim, dividido e hierarquizado por um muro muito bem construído historicamente pelos poderes que se sucederam na gênese da civilização ocidental, da qual somos herdeiros e que, ao longo dos tempos, se tornou detentora suprema da razão, difundindo a crença de que a ciência era um patrimônio seu e qualquer outra forma de saber não passava de crendices inferiores e superstições.

Realidades Universais, Reificação, fantasma do Uno - poderíamos multiplicar os exemplos desta atitude de espírito que pretende objetivar, colocar diante de si como objeto o fato social ou natural, a fim de assenhorear-se de sua riqueza e dominar o seu funcionamento. Tenhamos em mente que o processo de redução é sempre utilitarista. Impor uma organização social teocrática ou justificar uma exploração natural e social é sempre consequência de um pensamento redutor. (Maffesoli, 2007, p.65).

Pensamentos utilitários são facilmente transformados em pensamentos morais que servem para legitimar aparatos instituídos com a pretensão de reger a lógica do que "deve ser", ou seja, uma ordem moral de organização das coisas, dos homens e das sociedades. No entanto e a despeito disso, o que "é" tem prioridade sobre o que "deve ser". O que é simplesmente está no conhecimento empírico que permeia o cotidiano, nas incertezas, no movimento contínuo dos desafios que supera a construção meramente racional. Segundo Maffesoli, "Oideal do conhecimento cotidiano não é nem a certeza, nem mesmo a probabilidade em sentido matemático, senão somente a verossimilhança" (2007, p.209).

Relegado à margem das instituições detentoras do conhecimento, esse saber nascido do cotidiano, apelidado de "saber-fazer", esteve aquém (ou além) do institucionalismo moderno, por não se afirmar como uma ciência válida de estudo. A relevância formal era dada ao utilitarismo-tecnicista, forjado para a manutenção do sistema fabril de produção industrial do capital, ou das verdades absolutas produzidas pelos intelectuais das minorias dominantes, como propagação de sua ideologia e negação de qualquer outra forma de produção de cultura que contrariasse a certeza estruturada pelo social fixo e imutavelmente construída pelas sólidas identidades nacionais ou estatais.

Com suas referências comunitárias negadas desde o nascimento, o indivíduo precisava reinventar-se, sem que nada que viesse antes dele, ou que fosse forjado pelo presente facilmente superável estivesse equiparado ao "dever-ser". A manutenção dessa sociedade estava intimamente vinculada ao processo de conceituação lógica e racional de todo o conhecimento. A forma de educação válida é a formal, institucional, em que se aprende a executar o trabalho na função que se exerce, e a reconhecer conceitos válidos para a racionalidade.

O neotribalismo, porém, nos obriga a enxergar outra construção de saberes. Aquela de incertezas, mutabilidade constante e infinitos processos conceituais. O saber advindo da experiência cotidiana, um "co-naissance comum” (Maffesoli, 2006, p.239), representa um nascimento coletivo, a afirmação do saber gerado no seio da coletividade e para organização de suas identificações e continuidade desse território simbólico.

O saber oriundo da convivência proxêmica valida a centralidade subterrânea que mantém o vitalismo tribal dos atuais reagrupamentos sociais. É o reconhecimento de que, para além da homogeneização das culturas, existe um saber-dizer, uma sistematização e uma lógica de transmissão dos costumes característica da socialidade. Tal lógica não os cristaliza, mas é reflexiva, pois é oriunda da experiência, não validando uma prática, mas sendo. Ogerundismo desse saber demonstra a força do presente na sua construção, e seu inacabamento constante demonstra a vinculação de si com o imediato, com a atenção às necessidades cotidianas. 


\section{AS CONTRADIÇÕES: a hierarquia dos saberes}

De posse da noção dos saberes, podemos seguir no caminho da construção da Instituição Formal de Ensino. Para tanto, precisamos passar previamente pela organização de pensamento que inaugura essa estrutura como conhecemos hoje e observar como vem se transformando até a atualidade.

A estrutura de transmissão de conhecimento, que vigorava impressa nas grades curriculares de até bem pouco tempo atrás, no Brasil, tem seus precursores no cerne do pensamento moderno. Não afirmo que essa forma de tradução do conhecimento tenha sido a origem de toda e qualquer hierarquização das formas do saber, pois considero que cada sociedade, em cada época, tem seus próprios meios de transmissão de conhecimento e afirmação de poder para manutenção de seus padrões de convivência. Afirmo, porém, que a Modernidade vem a favorecer o meio de consolidação da educação burguesa institucionalizada, da qual herdamos o meio de compreensão do Ensino Superior.

A Idade Moderna, na cronologia da História Ocidental, de acordo com Vicentino (1997), tem início em $1453 \mathrm{com}$ a queda de Constantinopla, quando invadida pelos turcos otomanos, e seu fim é datado de 1789 com a tomada da Bastilha durante a Revolução Francesa. Esse período é marcado pela transição entre a ordem feudal da Idade Média e o capitalismo industrial, e ficou conhecido como Antigo Regime, na época dos Estados absolutos e do intervencionismo estatal na economiacaracterística do mercantilismo. A burguesia cristaliza seu poder econômico - apesar de não ter qualquer contrapartida no plano social e políticoconvivendo com o despotismo dos reis e a manutenção dos privilégios feudais - combinando o expansionismo, a exploração colonial, a ampliação comercial, o progressismo capitalista e os resquícios do feudalismo.

É nesse momento que entra em cena René Descartes (1596-1650). Ao propor o problema do conhecimento, ele determina dois campos do saber totalmente separados e distintos. Segundo Morin (2000, p. 27),
De um lado, o problema do Sujeito, do ego cogitans, do homem que por assim dizer reflete sobre si mesmo, e esse problema vai ser, deve ser aquele da filosofia. De outro lado, o problema daquilo que ele chama de res extensa, quer dizer, dos objetos que se encontram num espaço, e o universo da extensão do espaço é aquele oferecido ao conhecimento científico.

A partir dessa separação, o caminho da Filosofia e das Ciências passa a seguir a direção sugerida por Descartes, em que o sujeito é excluído do conhecimento científico.

Em seu Discurso do método, ele inaugura a Filosofia Moderna. Publicado no idioma Francês em 1637, época em que textos filosóficos eram escritos em latim e inacessíveis ao público em geral, afirmou ainda mais sua intenção de defender a popularização da razão para alcançar todas as pessoas dotadas de "bom senso", sem discriminação ou limitação de gênero, por considerar a razão inerente a todos, distinguindo-se apenas em sua aplicação.

Numa breve biografia na edição de 2008 do livro supracitado, Rosenfield descreve Descartes como aluno oriundo da escola jesuíta, mas alguém que acreditava que "a filosofia e a ciência estavam esclerosadas" (Descartes, 2008, p.6), e, para resgatar o princípio filosófico de busca da verdade de algo, necessitava de

... um pensamento autônomo, livre de quaisquer
amarras e, sobretudo, livre de toda espécie de
preconceito. Se cada um de nós almeja ter uma
ideia verdadeira, devemos preliminarmente afas-
tar este tipo de pré-conhecimento, de pré-con-
ceito, sedimentado no senso comum, impeditivo
de que se possa pensar diferentemente. [e
complementava] O senso comum de uma época,
qualquer que seja, não é nem pode ser critério de
verdade (2008, p.6).

Ele acreditava que, para reconhecer algo como verdadeiro, era preciso analisar racionalmente, a partir de um método baseado na dúvida e em sua hipérbole. Para sua própria reflexão, buscava apartar-se da vida social, concebendo a tarefa propriamente reflexiva, realizada no interior da consciência, numa razão voltada unicamente para si mesma, sem influências externas e internas, nem provenientes dos sentidos ou de preconceitos. Um método no qual os homens poderiam seguir com 
os passos seguros de uma sabedoria teórica e prática. Defendia a ideia de que a razão deveria permear todos os domínios da vida humana, numa atividade libertadora.

Imune ao erro, a razão tornara-se sinônimo de alma, mente, espírito, cuja propriedade essencial era o pensamento. Com sua separação do corpo, originaram-se dois tipos distintos de existência: a das ideias e do pensamento; e a material, atribuída à concepção de corpo como extensão. Nem a divindade escapa de sua análise racional, que já não admite limites.

Podendo ser utilizado por qualquer indivíduo, seu método pressupunha o abandono de opiniões sem fundamento sólido ou sustentação, pois era voltado para a busca da verdade, não da verossimilhança. Acreditava que seus procedimentos tornariam viável o progresso de toda a humanidade, a partir de conquistas graduais, primeiro no nível da individualidade, até ganharem os outros campos da vida.

Descartes (2008, p.54-55) apresentou quatro regras para a compreensão de seu método, simples e passíveis de adoção por qualquer pessoa:

1. Não aceitar nada como verdadeiro sem que passe pelo crivo da razão - seguindo uma ordem imune ao que é dado como verossímil pelo senso comum.

2. Dividir cada dificuldade em tantas parcelas quanto for possível, numa infinita simplificação, necessária para a delimitação perfeita de qualquer problema.

3. Conduzir os pensamentos numa ordem lógica, começando dos conhecimentos mais simples aos mais complexos - mesmo que um não preceda naturalmente o outro.

4. O procedimento deve dar lugar a tantas revisões quantas forem necessárias, podendo ser retomado e repetido por qualquer um - sendo verdadeiro aquilo que puder ser verificado.

A partir desses pressupostos, o autor também estabelece uma moral provisória para aqueles que se dedicarem a essa filosofia para que vivam segundo o mais provável e verossímil. Para tanto, estabeleceu mais regras (Descartes, 2008, p.59-68):
1. Obedecer às regras de cada país, seus costumes e leis, sem supressão da liberdade.

2. Ser resoluto e firme em suas ações, não seguindo as opiniões mais duvidosas, agindo de modo a chegar a algum lugar, mesmo que depois necessite reconhecer ter chegado a um lugar errado.

3. Mudar primeiramente a consciência individual para criar o hábito da razão.

4. A moral como escolha de vida, numa opção pelo bem maior, o da verdade como fruto de uma razão questionadora, metódica e aberta.

Apesar de sua intenção primeira ter sido apresentar os procedimentos que acreditou eficazes em sua vida na busca da verdade, e não determinar condicionantes a serem seguidos por sua sociedade, esses escritos determinaram o pensamento de toda uma época, vigorando ainda hoje como essência do pensamento ocidental em processo de revisão. Numa breve análise, é possível perceber que os princípios de seu método, em ordem de aparecimento, deram origem respectivamente: à negação do conhecimento cotidiano, à hiperespecialização, à hierarquização dos saberes, à quantificação e mensuração para a verificação do conhecimento. Eles são interdependentes e funcionam numa retroalimentação que vem determinando os rumos da construção dos conhecimentos no âmbito da cultura ocidental. Em última análise, atualmente, vêm servindo para o processo de afirmação do capitalismo como realidade econômica, bem como a subjugação de povos durante o colonialismo.

Dando sequência a esse processo epistemológico, cujos precursores foram René Descartes e Isaac Newton ${ }^{4}$ (1642-1727), surgiu o que Vicentino (1997) acredita ser o movimento que arquitetou as ideias que derrubaram o Antigo Regime: o Iluminismo. Caracterizado, segundo Gadotti (2004), pelo apego à racionalidade, pela luta em favor das liberdades individuais, contra o obscurantismo da Igreja e a prepotência dos governantes, a "Filosofia das Luzes" inaugurou uma nova forma de redenção da humanidade. Aquela que, para

Com o princípio da gravidade universal, Newton contribuiu para reforçar o fundamento de que o universo é governado por leis físicas e não submetido a interferências de cunho divino (Vicentino, 1997. p.235). 
Luckesi (1994), viria se opor à educação redentora preconizada pela Igreja: seria a redenção pela mente, uma readequação do mundo a partir de uma forma de pensar vinculada às mudanças sociais que despontavam. Gadotti (2004, p.88) afirma ainda:

O século XVIII é político-pedagógico por excelência. As camadas populares reivindicam ostensivamente mais saber e educação pública. Pela primeira vez um Estado instituiu a obrigatoriedade escolar (Prússia, 1717). Cresce, sobretudo na Alemanha, a intervenção do Estado na educação, criando Escolas Normais, princípios e planos que desembocam na grande revolução pedagógica nacional francesa do final do século. Nunca anteriormente se havia discutido tanto a formação do cidadão através das escolas como durante os seis anos de vida da Revolução Francesa. A escola pública é filha dessa revolução burguesa. Os grandes teóricos iluministas pregavam uma educação cívica e patriótica inspirada nos princípios da democracia, uma educação laica, gratuitamente oferecida pelo Estado para todos. Tem início com ela a ideia da unificação do ensino público em todos os graus. Mas ainda era elitista: só os mais capazes podiam prosseguir até a universidade.

Assim, a noção de saber vincula-se diretamente à educação escolar formal, instituída pelo Estado. A ideia do ensino universal como forma de eliminar a desigualdade vem como um marco para a sociedade da época. Vale ressaltar que essa desigualdade a ser eliminada é apenas um meio de acesso da burguesia ao poder, pois se admitia a desigualdade natural entre os homens. A educação oriunda dessa Revolução buscava formar o educando a partir da consciência de classe, centro do conteúdo programático. Gadotti explica que a burguesia ascendente queria uma educação que formasse cidadãos partícipes e uma nova sociedade liberal e democrática.

Para esse autor, o pensamento iluminista representou o fundamento da pedagogia burguesa, existente até hoje, através da transmissão de conteúdos e da formação social individualista. Essa classe percebeu a necessidade de oferecer a mínima instrução para a massa trabalhadora, dirigindo a educação para a formação do cidadão disciplinado. Destaco ainda, desse movimento, as ideias de Emanuel Kant (1724-1804), que acreditava que "o homem é o que a educação faz dele através da disciplina, da didática, da formação moral e da cultura." (Gadotti, 2004, p.90). Para Kant, o sujeito da educação precisava ser cultivado e civilizarse para corresponder à natureza. Devia atingir uma perfeição criada pelo homem, por meio da razão e livre do instinto. Assim, “... precisa da disciplina, que domina as tendências instintivas, da formação cultural, da moralização, que forma a consciência do dever, e da civilização como segurança social." (Gadotti, 2004, p.91). Kant sustentava que o homem tinha a capacidade de elevar-se mediante esforço intelectual contínuo e respeito às leis morais.

A doutrina burguesa nasce a serviço de uma liberdade associada ao conceito de propriedade e de liberalismo, a serviço da acumulação da riqueza. A burguesia impõe o saber institucionalizado como seu sistema de afirmação de poder, em que toma o controle da educação social de acordo com seus interesses, que passam a ser os interesses gerais de toda a sociedade. Ao arrancar o monopólio eclesiástico da educação, essa nova classe demonstrou, ainda cedo, que a igualdade entre os homens não estava de todo em seu projeto educacional. Tinha como princípio fundamental uma educação distinta para cada classe: a instrução para governar, direcionada para a classe dominante; e a educação para o trabalho, para a classe trabalhadora. Garantindo ainda que a educação desta última devesse ser ministrada a conta-gotas, pois a educação para o povo deveria fazer com que os pobres aceitassem sua condição de bom grado, como afirmaram Smith (1723-1790) e Pestalozzi (1746-1827), ambos citados por Gadotti.

Esse dualismo educacional entre as classes veio a ser sistematizado no século XIX, pelo pensamento positivista. Consolidando a concepção burguesa de administração do saber, o positivismo toma forma ao lado de seu antagonista direto, o marxismo. Ambos surgem como tentativas de sanar o que acreditavam ter sido uma derrota do Iluminismo. Gadotti explica que

Para Augusto Comte [1798-1857, positivista], a derrota do iluminismo e dos ideais revolucionários devia-se à ausência de concepções científicas. Já Marx [1818-1883, marxista] buscava as razões do fracasso na própria essência da revolução burguesa, que era contraditória: proclamava 
a liberdade e a igualdade, mas não as realizaria enquanto não mudasse o sistema econômico que instaurava a desigualdade na base da sociedade (2004, p.108).

Para Comte, uma verdadeira ciência analisaria todos os fenômenos como fatos, inclusive os humanos. As ciências da natureza, assim como as ciências humanas, precisavam ser neutras, afastando-se de qualquer preconceito ou pressuposto ideológico. O positivismo viria a consolidar a ordem pública, reinando absoluta, servindo de base para a formação científica da sociedade, instituindo a fé na ciência. Com o lema "Ordem e Progresso", o positivismo nasceu como filosofia, mas foi como ideologia que se afirmou, pregando a libertação social e política pelo desenvolvimento da ciência e da tecnologia, sob o controle das elites. Esse mesmo lema inspirou a Velha República e o golpe militar de 1964.

Para Maffesoli (2007), o positivismo talvez seja um mito fundador que serve à congregação de uma comunidade, que se ergue tal qual uma estátua confirmando os fiéis em sua fé e renegando os ímpios. Em sua atitude de espírito, instala a lógica do dever-ser, colocando sob a égide da razão todos os elementos da natureza e da sociedade. A vida social deve submeter-se aos direcionamentos dessa ciência que torna o fato social mensurável.

Ainda para esse autor, cada época apresenتิ ta seu próprio sistema de investigação e interpre凶 tação do ambiente social e natural, sendo difícil abstrair-se da tendência dominante. Ela precede as formas de organização do conhecimento como poder e controle social. Michel Foucault (1987, p.136) afirma que "Para as sociedades, gênese dos indivíduos, essas duas 'descobertas' do século XVIII [progresso e gênese] são talvez correlatas das novas técnicas de poder [...]". O isolamento dos indivíduos para o espaço autorizado de construção de saber, através da lógica positivista, leva o indivíduo a negar sua experiência como conhecimento sistematizado, valorando apenas as realizações de âmbito institucional, sendo facilmente subjugado pela sapiência hierarquicamente constituída pelo poder dominante. Procedendo à vigilân- cia mantenedora de seu poder, o positivismo busca tornar transparente toda a obscura vida em sociedade, recorrendo aos processos das ciências naturais para promover a remoção das trevas em que se encontram as realidades sociais, não podendo subsistir nenhuma ambiguidade ou equívoco. "O que está em jogo é uma sociedade perfeita” (Maffesoli, 2007, p.57).

O final do século XX, entretanto, mostra a saturação desta prática teórica, pois, como reforça Maffesoli (2007), uma ciência vinculada ao imperativo hegemônico do século XIX não compreende a "atividade comunicacional", caótica e ininterrupta, da atualidade. O que acontece é a suspeição da legitimidade de determinações de outras épocas que se pretenda fazer como referência insuperável no mundo do pensamento, tornarse uma verdade universal, sem fronteiras no espaço e no tempo.

É no domínio da existência social que a redução do conhecimento à ciência se torna abusiva. Faz-se necessário reconhecer que cada indivíduo apoia-se na experiência e na convivência para conhecer o que vive, e é essa imperfeição da dinâmica da sociedade que precisa ser expressa através de instrumentos igualmente flexíveis. Isso nos impele a buscar uma atitude mais apta a ocupar-se do cotidiano, assumindo seu relativismo.

Tal olhar pressupõe uma lógica do dia a dia diferente do absolutismo da verdade cartesiana, ou da síntese dialética - ambas ainda conceitualistas e sublimadoras das contradições: a primeira com sua total aniquilação, a segunda partindo dos antagonismos para propor uma síntese única - que legitimaram a busca da construção de sociedades perfeitas. Mas uma lógica contraditorial, que abandone o dever-ser do conceito uno e marginalizante, cerceador dos direitos de existência do que não pode abarcar. Dessa forma, aproprio-me dos dizeres de Maffesoli (2007, p.63) de que “... é preferível opor a moleza da noção à rigidez do conceito", ao assumir a atitude nocional, que, ao perceber a heterogeneidade, indica que um objeto é, ao mesmo tempo, diferentes coisas, evitando a existência de verdades universais. 
Não desconsidero o esforço positivista, que se justifica nas necessidades de afirmação de sua época, mas considero a sua saturação frente aos anseios da atualidade, em que a unidade do saber se encontra em processo de saturação, dando a vez a uma noção mole e polissêmica.

O pluralismo funcional vem a dar conta da polissemia da socialidade. Vem a ser a expressão metodológica da contradição e do heterogêneo. Reconhece o que é, antes de estabelecer o que deve ser. O retorno de valores considerados arcaicos território, ecologia, regionalismo e hedonismo vem para significar a inexistência de saberes absolutos. Pois, para Maffesoli (2007, p.68),

... se a utopia do conhecimento existe, se é legítima, isto não nos deve fazer esquecer que ela colide, em sua pretensão de tudo exaurir, com a dura realidade de um mundo social complexo, que parece sempre em fuga para adiante quando pensamos tê-lo apreendido de uma vez por todas. O que constitui a estruturação individual ou coletiva não é, decerto, o princípio de identidade, mas a contradição ou a alteridade. É então inútil querer formalizar ou quantificar as situações, as relações sociais ou as atividades múltiplas que exprimem, que põem em jogo tal alteridade.

Dessa forma, sai de cena o reducionismo utilitarista do conceito, e assume o palco a pluralidade funcional da epistemologia do cotidiano, que não pretende superar as contradições, mas, ao contrário, evidencia a heterogeneidade e a complexidade do presente e da sociedade.

(Recebido para publicação em 30 março de 2011) (Aceito em 28 de setembro de 2011)

\section{REFERÊNCIAS}

ANTUNES, Celso. Trabalhando habilidades: construindo ideias. São Paulo: Scipione, 2001. 79 p.

ANTONIAZZI, Maria Regina F. A historicidade da prática dos jesuítas no Brasil Colônia 1549-1697. 1993. 433f. Dissertação (Mestrado em Educação) - Faculdade de Educação, Universidade Federal da Bahia, Salvador, 1993.

BAUMAN, Zygmunt. O mal-estar da pós-modernidade. Trad. Mauro Gama e Cláudia Martinelli Gama. Rio de Janeiro: Jorge Zahar, 1998. 257 p.

BIÂO, Armindo; GREINER, Christine (Org.). Etnocenologia: textos selecionados. São Paulo: Annablume, 1998. 193p. BOSI, Alfredo. Dialética da colonização. 3.ed. São Paulo: Companhia das Letras, 1998. 412 p.

BURKE, Peter. O que é história cultural? Rio de Janeiro: Jorge Zahar, 2005. 192 p.

COSTA, Rogério Haesbaert da. $O$ mito $d a$ desterritorialização: do "fim dos territórios" à multiterritorialidade. 3.ed. Rio de Janeiro: Bertrand Brasil, 2007. 400p.

DAMÁSIO, Antônio R. O erro de Descartes: emoção, razão e cérebro humano. 2.ed. Trad. Dora Vicente e Georgina Segurado. São Paulo: Companhia da Letras, 2003.

DELORS, Jacques (Org.). Educação: um tesouro a descobrir. 3.ed. São Paulo: Cortez, 1999.

DESCARTES, René. Discurso do método. Trad. Paulo Neves. Porto Alegre: L\&PM, 2008. 123p.

FOUCAULT, Michel. Vigiar e punir: nascimento da prisão. 31.ed. Trad.Raquel Ramalhete. Petrópolis: Vozes, 2006. FREIRE, Paulo. Pedagogia do oprimido. 17.ed. Rio de Janeiro: Paz e Terra, 1987. 107 p.

Pedagogia da autonomia: saberes necessários à prática educativa. 26.ed. São Paulo: Paz e Terra, 1996. 148 p.

GADOTTI, Moacir. História das ideias pedagógicas. 8.ed. São Paulo: Ática, 2004. 319p.

GEERTZ, Clifford. O saber local: novos ensaios em antropologia interpretativa. 9.ed. Petrópolis, RJ: Vozes, 2007. $368 \mathrm{p}$.

HALL, Stuart. A identidade cultural na pós-modernidade. 11.ed. Rio de janeiro: DP\&A, 2006. 102 p.

HARVEY, David. A condição pós-moderna. 15.ed. São Paulo: Loyola, 2006. 349 p.

KOSHIBA, Luiz; PEREIRA, Denise Manzi Frayse. História do Brasil. 7. ed. São Paulo: Atual, 1996.

LAPLANTINE, François. Aprender antropologia. Trad. Marie-Agnès Chauvel. São Paulo: Brasiliense, 2007. 205p.

LE BRETON, David. A sociologia do corpo. 2.ed. Petrópolis: Vozes, 2007. 104 p.

LIBÂNEO, José Carlos. Didática. São Paulo: Cortez, 1994.

LOBATO, Lúcia Fernandes. Aspectos da filosofia ocidental cristã que influenciaram a formação da mentalidade brasileira de corpo. 1990. 118f. Dissertação (Mestrado em Ciências Sociais) - Faculdade de Filosofia e Ciências Humanas, Universidade Federal da Bahia, Salvador, 1990.

LUBISCO, Nídia M. L.; VIEIRA, Sônia C., SANTANA; Isnaia V. Manual de estilo acadêmico: monografias, dissertações e teses. 4.ed. rev.e ampl. Salvador: EDUFBA, 2008.

LUCKESI, Cipriano. Filosofia da educação. São Paulo: Cortez, 1994. 183 p.

MAFFESOLI, Michel. O conhecimento comum: introdução à sociologia compreensiva. Porto Alegre: Sulina, 2007. $295 \mathrm{p}$.

O tempo das tribos: o declínio do individualismo nas sociedades de massa. 4. ed. Rio de Janeiro: Forense Universitária, 2006. 298 p.

No fundo das aparências. 3.ed. Petrópolis: Vozes, 2005. $352 \mathrm{p}$.

MATURANA, Humberto R.; VARELA, Francisco J. A árvore do conhecimento: as bases biológicas da compreensão humana. 5. ed. São Paulo: Palas Athena, 2005. 288 p. 
MORIN, Edgar.; LE MOIGNE, Jean-Louis. A inteligência da complexidade. 3.ed. São Paulo: Peirópolis, 2000. 268 p.

Os sete saberes necessários à educacão do futuro. 11.ed. São Paulo: Cortez; Brasília, DF: UNESCO, 2006. $118 p$.

. A cabeça bem-feita: repensar a reforma, refor mar o pensamento. 12.ed. Rio de Janeiro: Bertrand Brasil, 2006. $128 \mathrm{p}$

Educação e complexidade: os sete saberes e outros ensaios. 4. ed. São Paulo: Cortez, 2007. 104 p.

Saberes globais e saberes locais: o olhar transdisciplinar. Rio de Janeiro: Garamond, 2008. 76 p.

MOSQUERA, Juan José Mouriño. Princípios da universidade no século XXI: universidade e produção do conhecimento. In: AUDY, Jorge Luis Nicolas; MOROSINI, Marília Costa (Org.) Inovação e empreendedorismo na universidade. Porto Alegre: EDIPUCRS, 2006. cap.3, p.79-88: Título original: Innovation and entrepreneurialism in the university.
SANTOS, Milton. Por uma outra globalização: do pensamento único à consciência universal. 17. ed. Rio de Janeiro: Record, 2008. 174p.

SILVA, Tomaz Tadeu da. Documentos de identidade: uma introdução às terias do currículo. 3.ed. Belo Horizonte: Autêntica, 2009.

SQUISSARDI, Valdemar. Universidade no Brasil: modelos clássicos aos modelos de ocasião. In: RISTOFF, Dilvo; SEVEGNANI, Palmira (Org.) Modelos institucionais de educação superior. Brasília: INEP, 2006. p.67-91.

VICENTINO, Cláudio. História geral. 8.ed. São Paulo: Scipione, 1997. $495 \mathrm{p}$ 


\section{TERRITORIALITY AND LOCAL KNOWLEDGE walls and frontiers in the construction of the academical knowledge}

\author{
Cecília Bastos da Costa Accioly
}

\section{TERRITORIALITÉS ET SAVOIRS LOCAUX: murs et frontières pour la construction du savoir académique}

\author{
Cecília Bastos da Costa Accioly
}

This article puts in context, the current paradigms which make possible the analyses of the system of cultural organization (the academical and local knowledge) and the institutions of higher education. Proposing a discussion of the different disciplinary and consolidated hierarchies in our society and in principle of overcoming through observation of regions of social construction frontier. Support to the relationships of culture formation knowledge, highlighting its moments of separation, hierarchy due to the application of the scientific method developer of academical knowledge construction; and the current discussion about its reunion under the view of a epistemology of everyday life.

KEY WoRDS: territoriality, local knowledge, academical knowledge, epistemology of everyday life.
Cet article situe les paradigmes actuels qui permettent d'analyser le système d'organisation culturelle (les savoirs académiques et locaux) et les institutions d'enseignement supérieur. On y propose la discussion des différenciations disciplinaires et hierarchiques enracinées dans notre société ainsi qu'un dépassement grâce à un regard sur les régions frontalières de la construction sociale. On y affirme la relation des savoirs qui forment les cultures, en soulignant le moment de séparation et de hierarchisation en fonction d'une mise en place de la méthode scientifique formatrice de la construction de la connaissance académique ainsi que l'actuelle discussion concernant sa ré-union dans l'optique d'une épistémologie du quotidien.

MOTS-CLÉS: territorialités, savoirs locaux, savoir académique, épistemologie du quotidien.

Cecília Bastos da Costa Accioly - Doutoranda pelo Programa de Pós-Graduação em Artes Cênicas da UFBA (Bolsa CNPQ). Professora Substituta do Departamento de Fundamentos do Teatro, Cursos de Licenciatura em Teatro e Bacharelado em Artes Cênicas - habilitações em Interpretação Teatral e Direção Teatral da Escola de Teatro da UFBA. Participa do Grupo Interdisciplinar de Pesquisa e Extensão em Contemporaneidade, Imaginário e Teatralidade (GIPE-CIT), UFBA. Publicações recentes: A Dança/ Educação na Contrução do Sujeito Reflexivo-Crítico. Revista da FACED (UFBA. Online), v. 17, p. 85, janjun. 98, 2010; Linke e Kluber Ross: a expressão de um regime em fase terminal. Cadernos do GIPE-CIT (UFBA), v. 22, p. 13-18, 2009. 
